\title{
Foot Reflex therapy and Energetic Chronotherapy Tools for Better Individual Healthcare and Welfare?
}

\author{
Pierre Bricage* \\ Health and Social Sciences Engineering, University of Pau \& Pays de l'Adour, France \\ *Corresponding author: Pierre Bricage, Faculty of Sciences, Health and Social Sciences, University of Pau \& Pays de l'Adour, Pau, \\ France. \\ To Cite This Article: Pierre Bricage. Foot Reflex therapy and Energetic Chronotherapy Tools for Better Individual Healthcare and Welfare?. Am \\ J Biomed Sci \& Res. 2019 - 2(2). AJBSR.MS.ID.000571. DOI: 10.34297/AJBSR.2019.02.000571
}

Received: February 22, 2019 | Published: March 28, 2019

Keywords: Chronobiology; Energetics reflexology; Randomized controlled trials; Systems Science

\section{Opinion}

The core of the Taoism philosophy of the optimal balance between Yin-Yang is the same as the meden agan Antique Greek philosophy [1]. Both agreed that sustainability is obtained neither through a greater efficiency (yang excess) nor through a greater resilience (yin excess) but with an in-between optimal balance, a window of viability. From their experience of interactions between Man and Nature, particularly in agriculture and health, the Chinese ancestors pointed to the ethics of the harmony and the order. Confucius said: "harmony is over all". To maintain the harmony between Man and Nature is the systemic way for sustainability and Societies have to respect the laws of Nature [2]. Taoism principles made their proofs in ecology [3], which is the economy of Nature: too little diversity (yang excess) leads towards breakage, too much (yin excess) leads to stagnation, and in economy: complementary currencies of diverse types enable economy to flow back towards greater sustainability [4].

Unless proved otherwise, every living system is rhythmic. Biological rhythms are essential components of homeostasis, and periodicity is inherited. Major pathologies result from rhythm disruption. Drugs show rhythmic variations in pharmacokinetics and pharmacodynamics [5]. Drugs abuse makes money but has triggered antibiotic resistances and environmental pollution. Other ways for quality-of-life restoration are needed [2]. Since, 5000 years, with antique Egyptian medicine and traditional Chinese medicine, foot reflex therapy was experimented and taught, with success. With time the energetic principles were forgotten, and it was misapplied and rejected by modern occidental chemical medicine. But with the failure of more and more aggressive treatments it was re-discovered. Foot reflex therapy can be used for diagnosis and as a tool [6] for chronic pain, vascular flow and lung or breast cancer treatments [7]. In a study, with a significant number of patients, $100 \%$ improvement was found [8]. How to summarize what the researchers know? How to use energetics reflex therapy tools? How to prove their efficiency?

Energetic reflex therapy results of many years of monitoring, with young and old men and women, taking drugs or not, can be randomized against foot massage or non-energetic reflexology results [9], as placebos, and general practitioner, acupuncturist, physiotherapist, rheumatologist, endocrinologist, neurologist or osteopath, results, as controls. Improvements were significant for: -exhaustion, insomnia, night awakenings, anxiety, hypersensitivity, depression, stress, agitation, confusion, dizziness, ictus, memory loss, headaches, migraine, -cognitive or motor dysfunction, traumas; -anorexia, loss of appetite, excess weight, obesity, -sugar or tobacco addiction, perverted taste sensation; -diarrhea, constipation, intestinal obstruction, abdominal discomfort, flatulence, colitis, -stomach discomfort, irritation, ebb or ulcer, dysphagia or dyspepsia, nausea, vomiting; -too low or too high blood pressure, palpitation, -low blood flow, venous or lymphatic drain disorders, edemas, haemorrhoids, veins varicose, syndrome of Raynaud; -hormonal disorder, pineal, pituitary or hypothalamus disorders, libido disorders; -bone, muscle, nerve or vessel pains, cramps, sciatic pain, facial neuralgia; -allergy, inflammation, skin disorders, eczema, acne, lupus; -osteoporosis, osteoarthritis, rheumatisms, fibromyalgia, hernia; -rhinitis, bronchitis, emphysema, asthma, -apnea, mucositis; -nephrite, cystitis, incontinence, -pancreatitis, diabetes; -kidney cysts, thyroid nodules. 
Taking into account chronobiology [10], reflexotherapy not only get success in diagnosis and treatments but also can be used to evaluate the efficiency of other therapies like lithotherapy [11]. Periodicity is a key component of therapy evolution and evaluation. Harmony preservation is governed by means of the law and the order. Our body is a living system of systems [1], a society of cell actors, that must be governed by the order, what allows to establish a hierarchy, a system of energetic controls, laws that govern physiological relations and survival rules. Every parts of our body are interacting together, for the best and for the worst. Only treating the right part, but in the right way and at the right time means to treat the whole body [11]: interaction is construction, construction is interaction [1].

\section{References}

1. Arendt J (1998) Biological rhythms: the science of chronobiology. J R Coll Physicians London 32(1): 27-35.

2. Bricage $P(1993)$ Are the lunar, radiative and position, cycles responsible for the entrainment of the periodic awakenings of the man night sleep? Biological Rhythms: from cell to man. Polytechnica, Paris, France. pp. 183-190.

3. Bricage P (2010) Bio-systemics, Teaching Systems \& Cybernetic Sciences in Higher Education. J Gu \& J Xu, Chengdu, Sichuan, (Eds) IASCYS Proceedings, PR China, p. 1-14.
4. Bricage P (2017) Use of Chronolithotherapy for Better Individual Healthcare and Welfare. Journal of Systems Science and Systems Engineering 26(3): 336-358.

5. Bricage P, Larroche D, Duverger Nedellec A (1990) Appraisement of the defoliator Lepidoptera associations in a hardwood forest. Acta Entomologica Vasconae 1: 5-26.

6. Byers D (2001) Better Health with Foot Reflexology. Ingham Publishing, Saint Petersburg, USA, p.182.

7. Cherkin DC, Sherman KJ, Kahn J, Wellman R, Cook AJ, et al. (2011) A Comparison of the Effects of 2 Types of Massage and Usual Care on Chronic Low Back Pain: A Randomized, Controlled Trial. Annals of Internal Medicine 155(1): 1-9.

8. Gu J, Zhu Z (1995) Wu-li Shi-li Ren-li Approach (WSR): An Oriental Systems Methodology. Systems Methodology. Midgley GL, Wiley J (Eds.) University of Hull, UK, p. 29-38.

9. Hodgson $H$ (2000) Does reflexology impact on cancer patients' quality of life? Nursing Standard 14(31): 33-38.

10. Lietaer B, Robert Ulanowicz, Sally Goerner (2009) Options for Managing a Systemic Bank Crisis. S.A.P.I.E.N.S. [Online] 2(1): 1-15.

11. Mei Y, Sikorskii A, Rahbar MH, Victorson D, You M (2012) Health-Related Quality-of-Life Outcomes: A Reflexology Trial With Patients With Advanced-Stage Breast Cancer. Oncology Nursing Forum 39(6): 568577. 